\title{
Availability of treatment drives decisions of genetic health professionals about disclosure of incidental findings
}

\author{
Erin Turbitt ${ }^{1,2}$, Michelle M Wiest ${ }^{3,4}$, Jane L Halliday ${ }^{2,5}$, David J Amor ${ }^{2,6}$ and Sylvia A Metcalfe ${ }^{\star, 1,2}$
}

Contrasting opinions exist regarding the disclosure of incidental findings detected through clinical genomic testing. This study used a discrete choice experiment to investigate genetic health professionals' preferences for the disclosure of incidental findings in an Australian paediatric setting. Four attributes of conditions relating to incidental findings were investigated: availability of prevention and treatment, chance of symptoms ever developing, age of onset and severity. Questionnaires from 59 Australian genetic health professionals were analysed. Results show that when evaluating incidental findings for disclosure, these professionals value the availability of prevention and treatment for the condition above all other characteristics included in the study. The framework of this discrete choice experiment can be used to investigate the preferences of other stakeholders such as paediatricians and parents about disclosure of incidental findings. The results of this study may be considered when assessing which categories of incidental findings are most suitable for disclosure in clinical practice.

European Journal of Human Genetics (2014) 22, 1225-1228; doi:10.1038/ejhg.2014.11; published online 5 February 2014

Keywords: discrete choice experiment; incidental findings; clinical genomic testing; genetic health professionals

\section{INTRODUCTION}

The application of clinical genomic tests, using microarray or sequencing technology, has improved diagnostic yields, especially in paediatric patients with unexplained developmental disability and/or congenital anomalies. ${ }^{1}$ A consequence of the untargeted nature of genomic tests is the increased likelihood of detecting an incidental finding (IF). The definition of an IF is variable, but in the context of genomic testing the term is used most commonly to describe a mutation that is detected but is unrelated to the original reason for testing. ${ }^{2}$

Although the number of clinical guidelines and recommendations regarding disclosure of IFs arising from clinical investigations has increased, there is a lack of consensus and a need for empirical data. ${ }^{3}$ Some authors favour patient autonomy, emphasising the importance of pre-test counselling and consent, ${ }^{4,5}$ whereas others highlight a perceived ethical obligation of the laboratory to seek and disclose information that is potentially lifesaving. . $^{2,6}$

This study aimed to investigate the most important characteristic of IFs that genetic health professionals consider when evaluating disclosure in an Australian paediatric setting using a discrete choice experiment (DCE). Use of DCEs is increasing in health-care research to study preferences of stakeholders in relation to complex goods or services. ${ }^{7}$ Hypothetical scenarios are presented and respondents select between two or more choices. Choice sets comprise multiple characteristics (attributes) of a particular good or service. Participants repeat this choice selection numerous times where each choice has varying attribute values (levels). This method simulates real-world scenarios and allows respondents' underlying preferences to be effectively studied. ${ }^{8}$

\section{MATERIALS AND METHODS}

Questionnaire design

Attributes consisting of multiple levels for the DCE were developed following a literature review and using data from 15 qualitative interviews with key informants. ${ }^{9}$ All potential attributes were assessed for inclusion, and, to reduce task complexity for respondents, ${ }^{7}$ four attributes (Figure 1a) were identified as major factors driving health professionals' decisions about disclosure of IFs. Attributes related directly to the condition/disease that may result from the IF, (a) availability of prevention and treatment; (b) age of onset; (c) severity; (d) likelihood of the condition developing.

Attributes (a) and (b) with two levels, attribute (c) with three levels, and attribute (d) with four levels result in $48\left(2^{2} \times 3^{1} \times 4^{1}\right)$ possible combinations. These 48 combinations were reduced to 16 scenarios using an orthogonal fractional main effects design, ${ }^{10}$ allowing a practical number of choices for respondents to answer. To create paired choices, a shift of one level was applied to each of the initial 16 scenarios. D-efficiency (precision of effect estimations) of the design was calculated as 96.7\%. Every respondent was presented with all 16 paired choice options in a randomised order. Figure $1 \mathrm{~b}$ shows an example choice set (see Supplementary Information for full questionnaire).

Minor changes were made to wording following piloting with 12 Master of Genetic Counselling students. Ethics approval was obtained from the Human Research Ethics Committee at the Royal Children's Hospital, Melbourne, Australia (HREC 31136F). All responses were confidential, voluntary and anonymous.

${ }^{1}$ Genetics Education and Health Research, Murdoch Childrens Research Institute, Melbourne, Victoria, Australia; ${ }^{2}$ Department of Paediatrics, The University of Melbourne, Melbourne, Victoria, Australia; ${ }^{3}$ Department of Statistical Science, University of Idaho, Moscow, ID, USA; ${ }^{4}$ Clinical Epidemiology and Biostatistics Unit, Murdoch Childrens Research Institute, Melbourne, Victoria, Australia; ${ }^{5}$ Public Health Genetics, Murdoch Childrens Research Institute, Melbourne, Victoria, Australia; ${ }^{6}$ Clinical Genetics Research, Murdoch Childrens Research Institute, Melbourne, Victoria, Australia

${ }^{*}$ Correspondence: Professor SA Metcalfe, Genetics Education and Health Research, Murdoch Childrens Research Institute, Royal Childrens Hospital, Flemington Road, Parkville, Victoria 3052, Australia. Tel: +61 38341 6309; Fax: +61 38341 6212; E-mail: sylvia.metcalfe@mcri.edu.au

Received 2 October 2013; revised 30 December 2013; accepted 7 January 2014; published online 5 February 2014 


\begin{tabular}{|c|c|c|}
\hline $\begin{array}{l}\text { Attribute of } \\
\text { incidental finding }\end{array}$ & \multicolumn{2}{|l|}{ Levels } \\
\hline $\begin{array}{l}\text { Prevention and } \\
\text { treatment }\end{array}$ & \multicolumn{2}{|l|}{$\begin{array}{l}\text { - Not available }(0) \\
\text { - Available (1) }\end{array}$} \\
\hline Age of onset & \multicolumn{2}{|l|}{$\begin{array}{l}\text { - Adulthood (0) } \\
\text { - Childhood (1) }\end{array}$} \\
\hline Severity of disorder & \multicolumn{2}{|c|}{$\begin{array}{l}\text { - Mild (0) } \\
\text { - Moderately severe (1) } \\
\text { - Very severe (2) }\end{array}$} \\
\hline Chance of developing & \multicolumn{2}{|l|}{$\begin{array}{l}\cdot 10 \%(0) \\
\cdot 40 \%(1) \\
\cdot 70 \%(2) \\
\cdot 100 \%(3)\end{array}$} \\
\hline \multicolumn{3}{|l|}{$\begin{array}{l}\text { b Example: } \\
\text { (tick one box only) }\end{array}$} \\
\hline \multicolumn{2}{|c|}{$\begin{array}{l}\text { Result A } \\
\text { A genetic change which relates to a disorder that: }\end{array}$} & $\begin{array}{l}\text { Result B } \\
\text { A genetic change which relates to a disorder that: }\end{array}$ \\
\hline \multicolumn{2}{|c|}{$\begin{array}{l}\text { - has prevention and treatment available } \\
\text { - develops in childhood } \\
\text { - will be very severe } \\
\text { - has a } 100 \% \text { chance of developing }\end{array}$} & $\begin{array}{l}\text { - does not have prevention and treatment } \\
\text { - develops in adulthood } \\
\text { - will be mild } \\
\text { - has a } 10 \% \text { chance of developing }\end{array}$ \\
\hline
\end{tabular}

This indicates that you would be more likely to include result $A$ on the report than result $B$

Figure 1 Discrete choice experiment design. (a) Attributes (characteristics) and levels (values) used in the discrete choice experiment. Ascribed numerical values for levels are shown in brackets. (b) Example of a discrete choice set provided to respondents in questionnaire. Respondents were presented with a hypothetical scenario involving a 3-year-old boy who is not reaching his developmental milestones. A genomic chromosomal microarray test is performed and an IF is detected. Respondents were asked to choose between characteristics of two different unnamed IFs and indicate which they would be more likely to disclose to the boy's parents.

\section{Sample and recruitment}

The questionnaire was administered on-line to genetic health professionals using listservs of the Human Genetics Society of Australasia: the Australasian Society of Genetic Counsellors (ASGC) and the Australasian Association of Clinical Geneticists (AACG).

\section{Analysis}

Data were analysed using a conditional logistic regression model. ${ }^{11}$ Levels for all attributes were dummy coded, where the effect of an attribute level is estimated relative to a reference point.

Subgroup comparisons investigated differences between genetic counsellors and clinical geneticists.

All analyses were performed using Stata 12.0 (Stata, College Station, TX, USA).

\section{RESULTS}

\section{Respondents}

A total of 59 respondents completed the questionnaire. Of these, 56 completed all 16 choices, one completed 11 choices, one completed 12 choices and one completed 15 choices. This resulted in a total of 1868 observations. Respondent characteristics are summarised in Table 1.

\section{Regression}

Positive coefficients represent the direction of respondents' preferences of the attributes. These preferences were for disclosure of an IF that has prevention and treatment available; manifests in childhood; is very severe; $100 \%$ likely to develop (Table 2a).

The attribute with the largest coefficient was prevention and treatment, indicating that respondents value this attribute above all others. Smaller differences were seen between the coefficients of the three remaining attributes.

Subgroup comparisons were made (Table 2b) between genetic counsellors and clinical geneticists. Clinical geneticists placed the highest value on the availability of prevention and treatment, second highest on severity of the condition, followed by age of onset and, lastly, likelihood of the condition developing. In comparison, although genetic counsellors also placed highest emphasis on availability of treatment, it was only marginally higher than age of onset, followed by likelihood of the condition developing, with the severity of the disorder having the least influence on their decision to disclose the IF. 
Table 1 Respondent characteristics

Total $(\mathrm{n}=56)^{\mathrm{a}}$

\begin{tabular}{lc}
\hline State & \\
ACT & $2(3.6 \%)$ \\
NSW & $23(41.8 \%)$ \\
QLD & $4(7.3 \%)$ \\
SA & $1(1.8 \%)$ \\
VIC & $16(29.1 \%)$ \\
WA & $9(16.4 \%)$
\end{tabular}

\section{Sex}

Female

Male

$45(80.4 \%)$

$11(19.6 \%)$

Age (years)

18-30

$31-40$

$41-50$

$51-60$

$>60$

Role

Clinical geneticist

$20(35.7 \%)$

Genetic counsellor

$36(64.3 \%)$

Years experience

$<5$

5-9

$20(35.7 \%)$

$11(19.6 \%)$

10-14

15-19

$\geq 20$

$12(21.4 \%)$

$6(10.7 \%)$

7 (12.5\%)

Health-care setting

Primary

Secondary

Tertiary

$8(14.3 \%)$

$4(7.1 \%)$

$44(78.6 \%)$

Type of clinic/hospital

Both public and private

$7(12.5 \%)$

Private

Public

2 (3.6\%)

Not applicable

$45(80.4 \%)$

$2(3.6 \%)$

aNot all respondents supplied complete demographic information.

\section{DISCUSSION}

This study is the first to use DCE to assess the preferences of genetic health professionals in Australia about the disclosure of IFs. Our results show that these professionals value most highly the availability of prevention and treatment for the related condition when assessing whether to disclose IFs in a paediatric setting. A lower preference was placed on the age of onset, severity and chance of the condition developing.

A recent publication reported on the development of a DCE to examine patient preferences for IFs, ${ }^{12}$ so our study, applying DCE to this area of research, is timely and with underlying rationale. Although a number of additional attributes could be considered such as cost for follow-up, importance of patient views and reproductive benefits, our study aimed to identify the most important attribute so we chose to restrict our DCE to four attributes. The results, and the choice sets developed, based on attributes and levels, can be used as a framework for future studies using other stakeholders such as paediatricians and parents.
Genetic health professionals in our study place a high value on availability of prevention and treatment of the condition related to the IF detected, invoking the ethical principle of beneficence. Of these professionals, clinical geneticists place significantly less emphasis on the age (childhood versus adulthood) at which the condition will manifest than availability of prevention and treatment. This questionnaire was implemented before the release of the American College of Medical Genetics (ACMG) guidelines, ${ }^{2}$ which list 24 conditions for IF disclosure, all with preventative measures or treatment options and include those with both childhood and adulthood onset, even for paediatric patients. European guidelines also recommend disclosure of incidental findings where prevention or treatment is available for the related condition. ${ }^{13}$

Some have argued that, use of whole-genomic testing, whereby IFs are actively sought and disclosed to patients, is in fact a form of population screening, analogous to newborn screening (NBS) or screening for hypertension. ${ }^{14}$ With this in mind, frameworks similar to those used in screening programmes could be adopted when assessing disclosure of IFs. For example, one of the most important considerations when evaluating conditions to be included in NBS is whether detection of the condition leads to a significant net benefit. ${ }^{15,16}$ Findings of our study are in-line with the basic principles used in design of NBS programmes, as disclosure of an IF will most likely lead to a significant net benefit if prevention and treatment is available.

Grove et al. ${ }^{17}$ in a qualitative study with 35 genetic health professionals found that participants gave patient autonomy primary importance. Another qualitative study with health professionals also involved the general public and parents whose child had undergone testing. They found that all participant groups agreed that categorising the results into 'packages' would be an effective strategy. ${ }^{18}$ The results of our study can contribute towards defining these categories to create a generic consent form and results disclosure policy.

Our subgroup analysis shows differences between preferences of genetic counsellors and clinical geneticists, with clinical geneticists placing comparatively higher emphasis on availability of prevention and treatment. Survey research from the United States has compared perspectives of genetic counsellors and clinical geneticists about ethical issues in clinical genetics. ${ }^{19}$ While they found little difference in most areas, their results suggest that compared with clinical geneticists, genetic counsellors favour autonomy and confidentiality more highly. The authors suggest that this may be due to differences in training of the two professions. For instance, genetic counselling training places higher emphasis on client autonomy than clinical genetics training. These are similar to differences seen in Australian training and could contribute to the different preferences related to disclosure of IFs. ${ }^{20,21}$

This study had some limitations. All members of the AACG and ASGC mailing lists (a total of 372 individuals) were sent invitation emails; however, these groups also comprise members who are not genetic counsellors or clinical geneticists and were ineligible for our study. Therefore, it is not possible to calculate an accurate denominator. Although our results may not be generalisable to all genetic health professionals, we have captured preferences of a wide variety of individuals, including health professionals from every Australian state. Another limitation is that real-life clinical situations are more complex than scenarios presented in our DCE and some respondents may have had difficulties responding out of context of the patient/family. They may have responded differently when face to face with a patient.

In conclusion, using the novel application of DCE we have investigated the preferences of Australian genetic health professionals for disclosure of IFs in paediatric patients. Genetic health professionals value availability of prevention and treatment above all other 
Table 2 Conditional logistic analysis regression results

\begin{tabular}{lcr} 
(a) Overall & & \\
Attribute & Coefficient $(95 \% \mathrm{Cl})$ & P-value \\
\hline Prevention and treatment & $2.72(3.07-2.38)$ & $<0.001$ \\
Age of onset & $1.74(1.99-1.49)$ & $<0.001$ \\
Severity of disorder & $1.76(1.52-2.00)$ & $<0.001$ \\
Chance of developing & $1.60(1.40-1.79)$ & $<0.001$ \\
\hline
\end{tabular}

(b) Subgroup comparison

Health Professional Role

Coefficient

Attribute

Clinical geneticist $(n=20)$

Genetic counsellor $(\mathrm{n}=36)$

P-value

Prevention and treatment

2.97

Age of onset

1.10

2.60

2.35

factors included in our DCE, with some variation observed between preferences of genetic counsellors and clinical geneticists. Differences observed between preferences of genetic counsellors and clinical geneticists may have an impact on practice. This DCE design could be used in other settings to investigate additional stakeholder or country specific differences on this topic. When evaluating conditions suitable for IF disclosure from whole-genomic testing, empirical data such as these can guide the decision-making process.

\section{CONFLICT OF INTEREST}

The authors declare no conflict of interest.

\section{ACKNOWLEDGEMENTS}

We thank the respondents in this study for their time and sharing their experiences and opinions. We thank Dr Melissa Hill for her input into the study design. This work was supported by the Victorian Government's Operational Infrastructure Support Program.

1 Sagoo GS, Butterworth AS, Sanderson S, Shaw-Smith C, Higgins JPT, Burton H: Array $\mathrm{CGH}$ in patients with learning disability (mental retardation) and congenital anomalies: updated systematic review and meta-analysis of 19 studies and 13,926 subjects. Genet Med 2009; 11: 139-146.

2 Green RC, Berg JS, Grody WW et al: ACMG recommendations for reporting of incidental findings in clinical exome and genome sequencing. Genet Med 2013; 15: 565-574.

3 Jackson L, Goldsmith L, O'Connor A, Skirton $\mathrm{H}$ : Incidental findings in genetic research and clinical diagnostic tests: a systematic review. Am J Med Genet 2012; 158: 3159-3167.

4 Rigter T, Henneman L, Kristoffersson $U$ et al: Reflecting on earlier experiences with unsolicited findings: Points to consider for next generation sequencing and informed consent in diagnostics. Hum Mutat 2013; 34: 1322-1328.

5 Berg JS, Khoury MJ, Evans JP: Deploying whole genome sequencing in clinical practice and public health: meeting the challenge one bin at a time. Genet Med 2011; 13: 499-504.

6 McGuire AL, Joffe S, Koenig BA et al: Ethics and genomic incidental findings. Science 2013; 340: 1047-1048.
7 Lancsar E, Louviere J: Conducting discrete choice experiments to inform healthcare decision making: a user's guide. PharmacoEconomics 2008; 26: 661-677.

8 Ryan M, Scott DA, Reeves C et al: Eliciting public preferences for healthcare: a systematic review of techniques. Health Technol Assess 2001; 5: 1-186.

9 Turbitt E, Halliday JL, Metcalfe SA: Key informants' perspectives of implementing chromosomal microarrays into clinical practice in Australia. Twin Res Hum Genet 2013; 16: 833-839.

10 Hahn G. Shaprio S: A Catalogue and Computer Program for the Design and Analysis of Orthoganol Symmetric and Asymmetric Fractional Factorial Experiments. General Electric Research and Development Center. Schenectady: New York, NY, USA, 1966.

11 Ryan M, Gerard K, Amaya-Amaya M (eds) Using discrete choice experiments to value health and health care; in The Economics of Non-Market Goods and Resources. vol 11, Springer: Dordrecht, The Netherlands, 2008.

12 Bennette CS, Trinidad SB, Fullerton SM et al: Return of incidental findings in genomic medicine: measuring what patients value - development of an instrument to measure preferences for information from next-generation testing (IMPRINT). Genet Med 2013; 15: 873-881.

13 Van El CG, Cornel MC, Borry P et al: Whole-genome sequencing in health care. Eur J Hum Genet 2013; 21: S1-S5.

14 Burke W, Antommaria AHM, Bennett R et al: Recommendations for returning genomic incidental findings? We need to talk! Genet Med 2013; 15: 854-859.

15 Kemper AR, Green NS, Calonge N et al: Decision-making process for conditions nominated to the Recommended Uniform Screening Panel: statement of the US Department of Health and Human Services Secretary's Advisory Committee on Heritable Disorders in Newborns and Children. Genet Med 2013; e-pub ahead of print 1 August 2013; doi:10.1038/gim.2013.98.

16 Cornel MC, Rigter T, Weinreich SS et al: A framework to start the debate on neonatal screening policies in the EU: an Expert Opinion Document. Eur J Hum Genet 2013; 22: $12-17$.

17 Grove ME, Wolpert MN, Cho MK, Lee SS-J, Ormond KE: Views of Genetics Health Professionals on the Return of Genomic Results. J Genet Couns 2013; e-pub ahead of print 2 June 2013; doi:10.1007/s10897-1013.

18 Townsend A, Adam S, Birch PH, Lohn Z, Rousseau F, Friedman JM: 'I want to know what's in Pandora's box': comparing stakeholder perspectives on incidental findings in clinical whole genomic sequencing. Am J Med Genet 2012; 158A: 2519-2525.

19 Pencarinha DF, Bell NK, Edwards JG, Best RG: Ethical issues in genetic counseling: a comparison of MS counselor and medical geneticist perspectives. J Genet Couns 1992; 1: 19-30.

20 Sahhar MA, Young M-A, Sheffield LJ, Aitken M: Educating genetic counselors in Australia: developing an international perspective. J Genet Couns 2005; 14: 283-294.

21 Alliman S, Veach PM, Bartels DM, Lian F, James C, LeRoy BS: A comparative analysis of ethical and professional challenges experienced by Australian and US genetic counselors. J Genet Couns 2009; 18: 379-394.

Supplementary Information accompanies this paper on European Journal of Human Genetics website (http://www.nature.com/ejhg) 